\title{
Traducción entregada frente a traducción publicada: reflexiones sobre la normalización en traducción editorial a partir de un estudio de caso
}

\section{Gemma Andújar Moreno}

Volume 61, numéro 2, août 2016

\author{
URI : id.erudit.org/iderudit/1037765ar \\ DOI : $10.7202 / 1037765$ ar
}

Aller au sommaire du numéro

\section{Éditeur(s)}

Les Presses de l'Université de Montréal

ISSN 0026-0452 (imprimé)

1492-1421 (numérique)

Découvrir la revue

\section{Résumé de l'article}

Seront présentés, dans ce travail, les résultats préliminaires d'une étude de cas dans la pratique réelle de la traduction éditoriale. À partir de l'analyse contrastive d'un corpus formé par un texte original français, le manuscrit de sa traduction remis à une maison d'édition espagnole et le livre finalement publié, le travail montre comment certaines divergences considérées comme des universels de traduction, telles que l'explicitation ou la suppression des répétitions, ne sont pas toujours directement imputables au traducteur mais qu'elles sont le résultat d'une stratégie de normalisation de la part des responsables de l'édition visant à faciliter la lisibilité du texte final. L'objectif de l'étude est de proposer une réflexion générale sur l'importance de prendre en compte le rôle des correcteurs et des éditeurs dans les analyses traductologiques de type contrastif pour mieux cerner la spécificité des différents agents impliqués dans les phases de production d'un livre publié.

\section{Citer cet article}

Andújar Moreno, G. (2016). Traducción entregada frente a traducción publicada: reflexiones sobre la normalización en traducción editorial a partir de un estudio de caso. Meta, 61(2), 396-420. doi:10.7202/1037765ar

Tous droits réservés (C) Les Presses de l’Université de Montréal, 2016
Ce document est protégé par la loi sur le droit d'auteur. L'utilisation des services d'Érudit (y compris la reproduction) est assujettie à sa politique d'utilisation que vous pouvez consulter en ligne. [https://apropos.erudit.org/fr/usagers/politiquedutilisation/] 


\title{
Traducción entregada frente a traducción publicada: reflexiones sobre la normalización en traducción editorial a partir de un estudio de caso
}

\author{
GEMMA ANDÚJAR MORENO \\ Universitat Pompeu Fabra, Barcelona, España* \\ gemma.andujar@upf.edu
}

\section{RÉSUMÉ}

Seront présentés, dans ce travail, les résultats préliminaires d'une étude de cas dans la pratique réelle de la traduction éditoriale. À partir de l'analyse contrastive d'un corpus formé par un texte original français, le manuscrit de sa traduction remis à une maison d'édition espagnole et le livre finalement publié, le travail montre comment certaines divergences considérées comme des universels de traduction, telles que l'explicitation ou la suppression des répétitions, ne sont pas toujours directement imputables au traducteur mais qu'elles sont le résultat d'une stratégie de normalisation de la part des responsables de l'édition visant à faciliter la lisibilité du texte final. L'objectif de l'étude est de proposer une réflexion générale sur l'importance de prendre en compte le rôle des correcteurs et des éditeurs dans les analyses traductologiques de type contrastif pour mieux cerner la spécificité des différents agents impliqués dans les phases de production d'un livre publié.

\begin{abstract}
This paper presents the preliminary results of a case study framed in the actual practice of translation for the publishing industry. Taking as a starting point the contrastive analysis of a corpus comprising a French original text, the draft of its translation submitted to a Spanish publishing house and the book which was finally published, the study shows how some shifts considered to be translation universals, such as explicitation or avoidance of repetitions, cannot always be directly attributed to translators but they are the result of an editing strategy aimed at normalizing the final text and improving its readability. The study puts forward a general reflection on why is important to take into account the role of correctors and editors in contrastive analyses of texts and their translations in order to better understand the specificity of the different agents involved in the many stages of publishing a book.
\end{abstract}

\section{MOTS-CLÉS/ KEYWORDS}

traduction éditoriale, manuscrit d'une traduction, correction, normalisation, normes d'édition

translation for the publishing industry, translation draft, correction, normalisation, editing norms

\section{Introducción}

La descripción de lo que es general y lo que es particular en traducción ha constituido una de las principales preocupaciones desde los inicios de la reflexión traductológica. Así, uno de los objetivos tradicionales de la rama descriptiva de los Estudios de Traducción ha consistido en explicar los cambios que se producen en las traducciones con respecto a sus textos originales (Bakker, Koster y Van Leuven-Zwart 1998). El 
centro de interés de las investigaciones llevadas a cabo desde esta perspectiva de comparación entre un original y una o varias traducciones ha sido determinar cómo se concreta la intervención del traductor sistematizando los indicios lingüísticos que constituyen un reflejo de su modo de actuar (Chevalier y Delport 1995). En el ámbito de la traducción editorial, por ejemplo, los análisis contrastivos se han centrado esencialmente en la descripción y explicación de las conductas traductoras, sin que hasta el momento se haya prestado una excesiva atención a la función de otros profesionales, como correctores o editores, en la configuración del producto textual que llega a manos del lector. En ocasiones, la intervención editorial, que puede afectar a todos los niveles del texto, implica transformaciones de gran calado en la traducción de las que no siempre tiene conocimiento el traductor. Carmen Francí Ventosa (2015), traductora literaria de reconocido prestigio, comenta una experiencia personal, por desgracia harto frecuente, en estos términos:

No hace mucho, una editorial se puso en contacto conmigo para que le cediera los derechos de Paraíso de Toni Morrison, obra que traduje hace más de quince años, ya que el contrato de cesión a la editorial que había editado la novela por primera vez se había extinguido. Por mero prurito profesional me propuse repasar mi traducción: sin embargo, lo que había imaginado una instructiva reflexión sobre los errores propios y lo mucho (o poco) que aprende un traductor con el paso del tiempo se convirtió en una sucesión de sorpresas y disgustos. Sin que se me hubiera comunicado en ningún momento (y sin que me hubieran enviado galeradas), la traducción que se había publicado contenía infinidad de cambios. A pesar de todo, llegados a este punto, intenté ver el lado positivo y, tras el soponcio inicial, me propuse analizar el proceso de corrección para ver cuál había sido el método del corrector y qué podía yo aprender de todo aquello (Francí Ventosa 2015).

Para explorar la vía de análisis apuntada en el pasaje que acabamos de citar, en las páginas que siguen presentamos los resultados de un estudio contrastivo donde se compara un texto original francés, el manuscrito de su traducción castellana entregada a una editorial y el texto finalmente comercializado. Al interesarnos por las divergencias entre la versión entregada y la versión publicada queremos modificar el centro de interés de la comparación textual para destacar el papel de la edición en la concreción del texto final y observar cómo, en ciertos casos, fenómenos considerados universales de traducción, como la explicitación o la evitación de repeticiones, no se explican por determinadas decisiones traductoras ni por las normas de traducción imperantes sino por las normas de edición que la editorial aplica con posterioridad al texto traducido.

\section{Marco teórico}

A principios de la década de 1990, Mona Baker acunó el término «universales de traducción» para referirse a las regularidades en las conductas traductoras que se repiten en los textos traducidos con independencia del par de lenguas implicadas en el proceso de transferencia textual (Baker 1993: 243). Entre estas regularidades que caracterizan la lengua traducida se encuentran la simplificación, la eliminación de las repeticiones, la explicitación o la normalización (Laviosa-Braithwaite 1998). Por su parte, Toury (1995 y 2004) propone una serie de leyes, de carácter probabilístico, entre las que se encuentra la interferencia y la estandarización. 
Aunque la utilidad e incluso la existencia misma de los universales de traducción ha sido puesta en tela de juicio desde diferentes perspectivas teóricas (por ejemplo, Pym 2008; Becher 2010a y 2010b; Mauranen y Kujamäki 2004), resulta innegable que la exploración de estos principios que gobiernan la producción de traducciones ha resultado muy provechosa para la rama descriptiva de los Estudios de Traducción y numerosos han sido los trabajos donde se ha adoptado un enfoque basado en corpus lingüísticos para explicar los cambios que se producen en las traducciones en comparación con sus textos originales, así como con otros textos producidos en la lengua meta (Olohan 2004; Zanettin 2012). Dichos cambios se explican por distintas condiciones causales, de tipo cognitivo, situacional y sociocultural, que Chesterman (2000) sintetiza en el siguiente cuadro:

CuAdro 1

Modelo de condiciones causales de Chesterman (2000: 20)

\begin{tabular}{|c|c|}
\hline $\begin{array}{c}\text { Socio-cultural conditions } \\
\Omega\end{array}$ & $\begin{array}{c}\text { (norms, history, ideologies, } \\
\text { languages) }\end{array}$ \\
\hline $\begin{array}{l}\text { Translation event } \\
\qquad,\end{array}$ & $\begin{array}{c}\text { (skopos, source text, computers, } \\
\text { deadline, pay...) }\end{array}$ \\
\hline $\begin{array}{c}\text { Translation act } \\
\Omega\end{array}$ & $\begin{array}{c}\text { (state of knowledge, mood, self- } \\
\text { image...) }\end{array}$ \\
\hline Translation profile & (linguistic features) \\
\hline$\sqrt{ }$ & \\
\hline $\begin{array}{c}\text { Cognitive effects } \\
\Omega\end{array}$ & $\begin{array}{c}\text { (change of cognitive or emotional } \\
\text { state...) }\end{array}$ \\
\hline Behavioural effects & (individual actions, criticism...) \\
\hline 凡 & (on target language, consumer \\
\hline Socio-cultural effects & $\begin{array}{c}\text { behaviour, discourse of translation, } \\
\text { status of translators...) }\end{array}$ \\
\hline
\end{tabular}

Entre las condiciones causales recogidas en el cuadro se encuentran factores de carácter interno, como las diferencias lingüísticas y de convenciones textuales entre el par de lenguas en juego, o las características discursivas del texto original, y factores externos como la función de la traducción y las posiciones que ocupan las culturas emisora y receptora en el mapa cultural mundial. Ahora bien, el acto traductor supone la interposición entre emisor y receptor de una tercera subjetividad, la del traductor, un «ser interviniente», en palabras de Maier (2007: 2), que lee e interpreta el texto original. Así, afirmaciones como «los traductores tienden a reducir o eliminar las repeticiones léxicas», «los traductores tienden a explicitar» o «los traductores prefieren evitar la vaguedad semántica» son afirmaciones que sitúan al traductor como centro del modelo causal, pues es el traductor quien, con su potestad de intervención en el texto (Meier 2007; Munday 2007), actúa como filtro decisivo y último en la concreción del producto textual final: 
All statements about laws and universals, if they are given causal force, must thus accept that all causal influences are filtered through the translator's own mind, through subjective decisions taken at a given moment (Chesterman 2000: 26).

No obstante, erigir al traductor en centro único del modelo causal implica perder de vista, en cierta forma, que la autoría de una traducción no suele ser exclusiva de éste, pues en la concreción del texto traducido que llega a las manos del lector intervienen diversos agentes con funciones propias. Entre ellos destaca la figura del editor, como acertadamente señala Bisiada (2014):

In the study of translations, we usually think of the translated text as being authored solely by the translator. The role of editors in the production of translations has not been pursued to a noticeable extent (...). Editing translations 'can usually be accomplished without referring back to the original text' (Nida 1997: 10), but editors can also revise the translation by reference to the ST, which may imply significant changes to the translation decisions (Bisiada 2014: 3).

Por consiguiente, la edición del texto, entendida ésta en un sentido amplio que incluye las correcciones ortotipográficas y de estilo, suele comportar transformaciones con respecto a las decisiones traductoras iniciales, a todos los niveles del texto, que deberían tomarse en consideración al estudiar las posibles divergencias entre original y traducción, pues no siempre los fenómenos que se plasman en la traducción publicada son atribuibles al propio traductor. Ya en 1995, en su obra Descriptive Translation Studies and Beyond, Gideon Toury advertía del peligro que supone simplificar la figura del traductor y del proceso de traducción en los estudios contrastivos:

More problematic still, the comparative method entails an inherent weakness precisely as far as translation processes are concerned. As long as it is only pairs of target vs. source texts that are available for study, there is no way of knowing how many different persons were actually involved in the establishment of a translation playing how many different roles. Whatever the number, the common practice has been to collapse all of them into one person and have that conjoined entity regarded as 'the translator' (Toury 1995: 183).

De estas palabras de Toury se desprende que, para profundizar en el conocimiento del proceso de traducción, es preciso descomponer sus múltiples fases y acotar, en la medida de lo posible, la intervención de cada uno de los agentes implicados en cada una de las fases:

If dubious statements on translational procedures or strategies are to be avoided, ways should be found to break the fictitious constructs of both 'translator' and 'translation process' into their components and to start relating them to each other (Toury 1995: 184).

Algunos trabajos recientes exploran ya esta vía de análisis que Toury sugería en la década de 1990. Así, por ejemplo, Bisiada (2014) recurre a un corpus alemán-inglés formado por versiones manuscritas sin editar y versiones publicadas de los mismos artículos de temática económica para afirmar que la división de un enunciado alemán en dos enunciados en su traducción inglesa constituye una estrategia de explicitación no sólo atribuible a los traductores, sino también a los editores, que pretenden con ello mejorar la legibilidad de los textos utilizando enunciados más breves. Krueger (2012), apoyándose en el análisis de un subcorpus de textos traducidos, otro de textos editados y otro de textos sin editar, enmarca los universales de traducción en el pro- 
ceso de mediación del que es objeto la lengua traducida para afirmar que: «To investigate the effects of translation without the interference of editing it may in fact be necessary to compare unedited original text production with draft (i. e., unedited and unrevised) translations» (Krueger 2012: 384). El estudio de caso ${ }^{1}$ que presentamos a continuación pretende constituir una aportación en este sentido, pues a diferencia de los análisis en los que se compara el original y su traducción, se introduce en la comparación la versión manuscrita de la traducción para identificar tendencias en las conductas editoras.

\section{La normalización en traducción editorial: estudio de caso}

\subsection{Diseño del estudio y consideraciones metodológicas previas}

La traducción editorial es un campo de actividad traductora que, tradicionalmente, ha estado estrechamente vinculado a los géneros literarios (Fouces González 2011). Sin embargo, se trata de un ámbito más amplio de actividad traslativa donde los textos traducidos, de temáticas y géneros discursivos diversos, están destinados a ser publicados por editoriales. ${ }^{2}$ La rúbrica comprende, pues, «les textes traduits destinés à la publication [...], élaborés par des traducteurs professionnels pour le compte des maisons d'édition à partir de textes publiés dans une autre langue» (Dragovic-Drouet 2005: 153).

La denominación «traducción editorial» resulta una etiqueta útil para los análisis contrastivos en la medida en que, al tratarse de una rúbrica inclusiva y centrada en un campo de actividad profesional, permite superar las clasificaciones tradicionales de la traducción basadas en el tipo de texto o en la modalidad de traducción (Luna Alonso 2013: 131; Hurtado Albir 2001: 45-51). Asimismo, al centrar el foco de atención en el campo de actividad, con los condicionantes que le son propios, permite contextualizar el proceso de traducción como uno de los eslabones integrantes de la cadena de producción de un libro, un proceso complejo en el que intervienen múltiples agentes con funciones y cometidos diversos.

El corpus analizado en el estudio de caso está formado por tres documentos: el

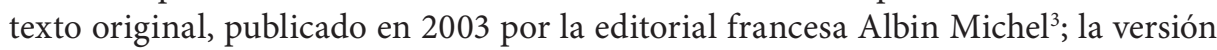
de la traducción entregada a Ediciones Paidós Ibérica (manuscrito inédito de la traductora $)^{4}$ y la versión publicada finalmente por la misma editorial ${ }^{5}$, tras haber pasado el manuscrito por el filtro de la corrección. ${ }^{6}$

La versión de la traducción entregada a la editorial constituye una fuente primaria de análisis traductológico que puede considerarse un manuscrito si nos atenemos a la definición que de este concepto ofrecen los diccionarios («Texto original de una publicación $»^{7}$ ). Munday (2013) destaca el valor de estos documentos personales del traductor para proporcionar claves sobre el proceso de traducción:

Just as valuable in this regard are draft manuscripts and papers. These are unpublished textual sources, preceding and building to the TT itself. They are interim products which offer crucial and more direct access to the creative process that is [...] translation and providing written evidence of the translator's decision-making (Munday 2013: 126).

Este manuscrito inédito constituye el borrador final de la traducción, que la traductora ha considerado poseedor de la calidad suficiente como para ser entregado a la editorial para su publicación. Finalmente, el corpus se completa con el libro 
comercializado a partir de la versión entregada, tras haber sido objeto el manuscrito de una corrección tanto ortotipográfica como de estilo.

Los estudios traductológicos sobre documentos personales de traductores, como el que presentamos, no han tenido excesivo peso en el marco de los Estudios de Traducción y, por lo general, se han enmarcado tradicionalmente en el campo de la traducción literaria. Dichos trabajos suelen analizar de forma contrastiva las sucesivas versiones de una misma traducción con respecto del original para poner de manifiesto cómo los traductores no producen la versión final de golpe, sino en un vaivén de sucesivas autocorrecciones. El proceso de traducción se revela, pues, como un «self-monitoring process» (Toury 1995: 184) donde cada una de las versiones es una prueba en un proceso de toma de decisiones que culmina en la traducción final. En esta línea se sitúan estudios como Toury (1995: 193-205) o trabajos más recientes como Munday (2013). En este último, además del análisis del propio autor sobre los manuscritos de la traducción de Les Choses, de Georges Perec, realizada por David Bellos, se citan otros trabajos con esta orientación como los de Pijuan Vallverdú (2007), Bush (2006), Jones (2006) o Filippakopoulos (2008).

A diferencia de estos trabajos, la novedad del estudio de caso que presentamos en estas páginas radica en que objeto de interés es el siguiente eslabón en la cadena de traducción editorial: la recepción de la traducción por parte de la editorial (agente iniciador del proceso traductor) y el análisis del texto final publicado en comparación con el texto entregado. En la siguiente figura hemos representado gráficamente nuestro centro de interés enmarcándolo en las sucesivas fases de emergencia de un libro traducido por encargo de una editorial:

FIGURA 1

Fases de emergencia de un libro traducido

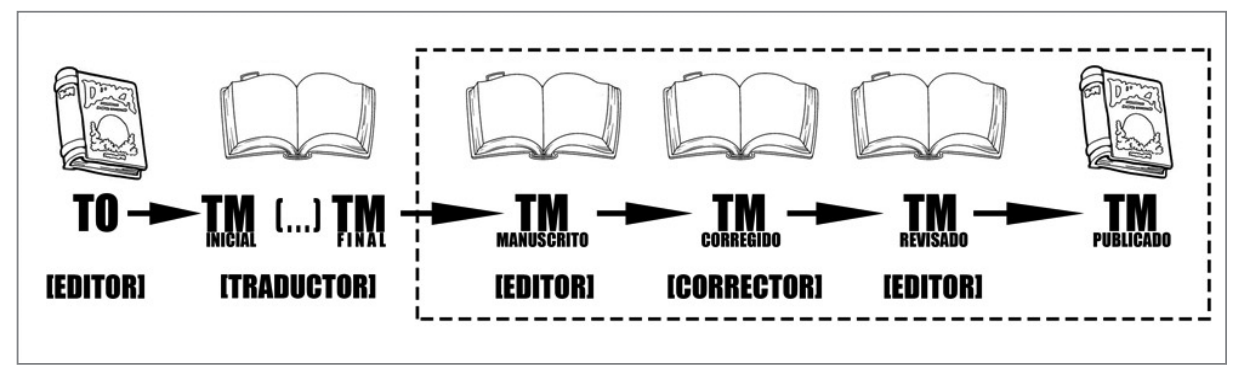

La descripción sistemática de los cambios y correcciones editoriales ${ }^{8}$ para identificar grandes tendencias permite describir, en un primer momento, las decisiones traductoras y analizar posteriormente cómo han sido recibidas por la editorial: hasta qué punto se han respetado en las correcciones posteriores, qué cambios se han introducido y si dichos cambios, en el caso de que los hubiere, apuntan en alguna dirección en cuanto a las normas imperantes. Se trata, pues, de un análisis descriptivo de tres productos textuales que posee la clara vocación de proporcionar claves sobre el proceso de traducción y la plasmación de su resultado en un libro comercializado, puesto que: 
A useful as descriptive translation studies are for the identification of trends of translation shifts and translational norms in published texts, their scope is inevitably limited if they do not seek to combine analysis of the translated product with an investigation of the translation process (Munday 2013: 134).

Somos perfectamente conscientes de que «obviously, the study of drafts is objectively more solid if it is carried out by a third party» (Munday 2013: 129). En este caso, que la autora de este trabajo y la traductora de la obra sean la misma persona constituye una debilidad metodológica, puesto que esta circunstancia no garantiza plenamente la validez ecológica y la objetividad experimental (Neunzig y Tanqueiro 2007). Hemos tratado de subsanarlo en la medida de lo posible mediante el distanciamiento en el análisis contrastivo del corpus. Con todo, podría afirmarse que también ha constituido una cierta ventaja, puesto que ha permitido acceder fácilmente a un documento personal que, de otro modo, habría sido difícil de obtener, así como un conocimiento pleno de las características del encargo de traducción: el desarrollo de las sucesivas fases del proceso de traducción y, sobre todo, las instrucciones explícitas e implícitas que impuso la editorial al proyecto. En el apartado siguiente, profundizamos en todos estos aspectos del encargo de traducción para contextualizarlo en el marco general de una práctica profesional real.

\subsection{Descripción del encargo de traducción editorial}

En los estudios traductológicos sobre libros publicados por editoriales, como el presente trabajo, se impone abordar, en primer lugar, el perfil del iniciador, así como el proceso de elaboración del encargo dentro de la cadena del libro y el resultado como producto (Luna Alonso 2013: 133). En este caso, el iniciador del encargo es Ediciones Paidós Ibérica. Fundada en Buenos Aires en 1945, esta editorial posee uno de los catálogos de referencia en ciencias humanas y sociales, formado por más de dos mil títulos enmarcados en colecciones de filosofía, política, psicología, historia, comunicación, cine o divulgación científica en general. ${ }^{9}$ En 2003, siguiendo el "pattern of conglomerization» que afecta al sector editorial europeo, donde el control del mercado se reparte entre un número reducido de grandes grupos (Hale 2001: 191), Paidós fue absorbida por el Grupo Planeta y dejó de constituir una editorial independiente para pasar a integrarse en uno de los grupos de comunicación con mayor peso a nivel estatal e internacional. Esta absorción, además de un cambio de sede y de organización interna de la editorial a todos los niveles, trajo aparejadas importantes consecuencias para las condiciones laborales de los traductores autónomos. Aunque no podemos dejar de mencionarlo, profundizar en esta cuestión superaría ampliamente los límites de este trabajo.

Este es el contexto en el que, en 2010, una de las editoras de mesa de Paidós encarga la traducción de la obra francesa analizada: Confession d'un philosophe. Réponses à André Comte-Sponville. No se trata, pues, de un texto literario sino de un ensayo de tipo humanístico sobre diversos temas de reflexión filosófica. Su autor, Marcel Conche (Altillac, Francia, 1922), ha sido considerado por los especialistas como uno de los filósofos de la época moderna más originales e influyentes en lengua francesa. ${ }^{10}$ Es un autor canónico en el campo de la filosofía, avalado por numerosos premios y reconocimientos. Con una extensa obra donde aborda importantes cuestiones de metafísica (en libros como L’Aléatoire, 1990; Vivre et philosopher, 1992; 
Temps et destin, 1999; Présence de la nature, 2001; Montaigne ou la conscience heureuse, 2002; o Philosopher à l'infini, 2005, por citar solo algunos), es también catedrático emérito de filosofía en la Sorbonne y miembro de la Academia de Atenas. Entre las distinciones de las que ha sido merecedor, destaca el Grand Prix Moron (1996), la Medalla de Honor de la Sorbonne (1980) y un reconocimiento al conjunto de su trayectoria por parte de la Académie française (1997).

A pesar de la gran influencia que ha tenido el pensamiento y la obra de Marcel Conche en los filósofos franceses posteriores a su generación, se trata de un autor poco conocido en lengua castellana. Según la base de datos de libros editados en España del Ministerio de Educación, Cultura y Deporte ${ }^{11}$, únicamente se han traducido al castellano tres de sus obras: Heidegger en la tormenta (Barcelona: Melusina, 2006); Del amor. Reflexiones descubiertas en un viejo cuaderno de dibujo (Barcelona: Paidós, 2010), ambas firmadas por Pilar Sánchez Orozco, especialista en este autor, y Confesiones de un filósofo (Barcelona: Paidós, 2010), la traducción analizada en el estudio de caso. Antes de la publicación de estas obras, la principal vía de acceso en lengua española al pensamiento de este autor era la tesis doctoral de Pilar Sánchez Orozco, Actualidad de una sabiduría trágica: el pensamiento de Marcel Conche (2003).

El encargo de traducción editorial analizado responde a la voluntad explícita por parte de la editorial de dar a conocer la obra de Conche a un público español no especialista. El original francés, Confession d'un philosophe. Réponses à André ComteSponville, está concebido como un «livre d'entretiens» (Conche 2003: 9) donde se reproduce una conversación sobre temas personales y filosóficos diversos entre dos pensadores de dos generaciones muy distintas: el propio Conche y André ComteSponville, el maestro y uno de sus discípulos más eminentes. Tal y como afirma este último en el prefacio, el objetivo de la obra es esencialmente divulgativo, pues pretende ofrecer una vía de acceso al pensamiento de Conche para un público amplio, sin conocimientos profundos de filosofía:

La philosophie est un travail, et Marcel Conche le sait mieux que personne. Mais ce travail n'est pas réservé aux professionnels, aux spécialistes, c'est-à-dire aux enseignants de philosophie. Il s'adresse à tous, au moins en droit, et à chacun, s'il consent de penser librement. C'est ce qui justifie le présent ouvrage, qui voudrait offrir une porte d'entrée, ou plusieurs, dans la pensée de ce maître exigeant et chaleureux (André ComteSponville, en Conche 2003: 10)

El libro se plantea, pues, como un «dialogue» (Conche 2003: 11) entre maestro y discípulo sobre temas como el amor, la felicidad, la actitud ante la muerte, el humanismo, la libertad o la clonación. Además de estos temas generales de reflexión, que podrían resultar interesantes y no excesivamente arduos para un público no especialista, la editorial consideró que la figura de André Comte-Sponville también podría contribuir a la difusión del libro. No hay que olvidar que, en traducción editorial, los libros publicados son productos comerciales con fines lucrativos y que «despite their cultural significance, the production of books is entirely regulated by commercial forces» (Hale 2001: 190). André Comte-Sponville, con dieciocho obras publicadas en castellano por Ediciones Paidós entre 2001 y 2014 (como La felicidad, desesperadamente, 2010; Pequeño tratado de las grandes virtudes, 2013; o la más reciente, de 2014, El alma del ateísmo, por citar sólo algunas) es un filósofo ampliamente conocido por el público y sus obras de divulgación han cosechado buenas cifras de ventas, por lo que podría constituir un aliciente para el lector en el momento de plantearse la adquisición del libro de Conche. 
La editora de mesa no planteó el encargo con instrucciones concretas sobre cómo debía recuperarse el texto original en castellano; las únicas indicaciones fueron de tipo genérico: que la traducción fuera fluida y de lectura ágil (parafraseándolo en términos más coloquiales: «que se lea bien»). Asimismo, permitió adjuntar en un documento independiente los comentarios que la traductora tuviera a bien trasladarle, ya fuera sobre dificultades específicas de traducción, sobre cuestiones más generales del estilo del autor o sobre cualquier aspecto que debiera tenerse en cuenta en la edición posterior. En este documento se incluyeron, finalmente, comentarios sobre problemas de transcripción de vocablos filosóficos en griego, cuestiones relativas a la citación de obras de referencia e instrucciones específicas para respetar la distribución en versos de poemas reproducidos literalmente de obras ya publicadas. Una vez entregada la traducción y obtenido el visto bueno de la editorial, la traductora no recibió galeradas del texto ni tuvo más noticia del proceso de edición hasta que recibió un ejemplar del libro ya publicado. A continuación, describiremos las principales diferencias entre la versión entregada y la versión publicada en los niveles microtextual y macrotextual haciendo especial hincapié en las consecuencias que implican para los lectores del libro publicado.

\subsection{Versión entregada frente a versión publicada: análisis contrastivo}

El libro original de Marcel Conche es un texto escrito que, sin embargo, presenta un importante componente de oralidad, ya que está concebido como un «livre d'entretiens» (Conche 2003: 9) con un proceso de elaboración particular: ComteSponville enviaba por correo a Marcel Conche las preguntas que abren cada uno de los capítulos del libro y desencadenan la reflexión que se expone en ellos. A su vez, Conche devolvía por correo la respuesta, lo que suscitaba otra nueva pregunta. El texto final posee, pues, un importante componente oral producto de la imitación de una conversación entre los dos filósofos; en palabras de Comte-Sponville, la elaboración del libro supuso "[...] un parcours discontinu, donc, "à sauts et à gambades", comme disait Montaigne, qui voulait retrouver à travers l'écrit, quelque chose de la conversation ou, comme disait encore Montaigne, de l'“art de conférer"» (Conche 2003: 11).

No se trata, pues, de una conversación entre filósofos sino de un monólogo de Conche desencadenado a partir de una pregunta de Comte-Sponville. Tampoco es una interlocución en presencia, pero sí se intenta generar esa impresión en el lector, no tanto mediante el uso de giros o expresiones marcadamente coloquiales sino explotando una serie de rasgos sintáctico-estilísticos particulares. Así, la oralidad fingida puede definirse, desde la perspectiva ofrecida por Goetsch (2003) y Koch y Osterreicher (2007), como la ficción o ilusión de oralidad que evoca un texto escrito mediante la explotación de un conjunto específico de recursos propios de la lengua oral. Para conferir verosimilitud a los discursos planificados, los autores seleccionan un conjunto de rasgos lingüísticos y rechazan otros. En el modelo de Koch y Osterreicher (2007), la dicotomía tradicional de «oral» frente a «escrito» se sustituye por un continuum definido por los polos del «lenguaje de la inmediatez» y el «lenguaje de la distancia», con independencia del medio o el canal donde se produzca. El lenguaje de la proximidad puede ser, pues, de concepción oral aunque se produzca en un medio escrito, mientras que el lenguaje de la distancia puede ser de concepción 
escrita, aunque ocurra en un medio oral. La oralidad fingida constituye una modalidad específica y estructurada que se sitúa en este continuum.

Los cambios que se han producido entre la versión entregada y el libro publicado están estrechamente relacionados con la mímesis de la oralidad en el texto escrito y pueden adscribirse a dos categorías generales, la modificación y la explicitación, que recogemos en el siguiente cuadro:

CUADRO 2

Correcciones editoriales clasificadas por categorías

\begin{tabular}{|l|l|}
\hline \multicolumn{2}{|l|}{ Correcciones editoriales } \\
\hline \multirow{4}{*}{ Modificación } & - Repeticiones léxicas y \\
& morfosintácticas \\
& - Orden oracional \\
& - Signos de puntuación \\
\hline \multirow{3}{*}{ Explicitación } & - Formas verbales \\
& - Conectores discursivos \\
& - Otros mecanismos cohesivos \\
\hline
\end{tabular}

Estas dos categorías generales de divergencias entre la versión entregada y la versión publicada podrían adscribirse a lo que Gideon Toury define como «nonobligatory shifts» (Toury 1995: 57): aquellas variaciones no impuestas por diferencias en la estructura sintáctica y semántica del par de lenguas en juego sino motivadas por las normas imperantes; en este caso, las normas de edición son las que explican los contrastes intertextuales, provocados por una intervención normalizadora del editor que tiene por objetivo obtener un texto meta más convencional, más usual y de lectura más fluida. En los apartados siguientes describimos con mayor precisión estas alteraciones ilustrándolas con ejemplos representativos de los fenómenos señalados.

\subsubsection{Modificaciones}

La modificación comprende las alteraciones que afectan a la repetición léxica, al orden del enunciado y a determinados signos de puntuación relacionados con la modalidad sin que se produzcan forzosamente por ello cambios radicales de sentido en el texto publicado.

\subsubsection{Repeticiones léxicas y morfosintácticas}

Hatim y Mason (1995: 252) denominan «recurrencia estricta» a la repetición de una misma unidad léxica en distintos momentos del texto. Se trata de un mecanismo de articulación y formulación del discurso motivado por un propósito retórico global y puede vincularse a una intencionalidad del emisor, ya sea planificada o inconsciente, puesto que sirve para vehicular distintos efectos discursivos: puede servir para expresar sorpresa ante lo que se está oyendo, transmitir énfasis en determinadas ideas o conceptos y lograr así que permanezcan más tiempo en la mente del lector, reafirmar puntos de vista propios o retomar el discurso tras una interrupción, entre otras funciones. En el discurso de Conche la repetición léxica posee principalmente un valor enfático, pues el autor la utiliza para producir una detención del movimiento discur- 
sivo y destacar así un concepto, filosófico normalmente, «fijándolo» por más tiempo en la mente del destinatario.

Las correcciones editoriales mantienen de manera casi generalizada las repeticiones léxicas y morfosintácticas, ya sean simples o complejas. Sin embargo, en algunos casos se introducen ciertas modificaciones que apuntan en una misma dirección: cuando en el original se acumula este fenómeno estilístico, el texto publicado tiende a rebajarlas, ya sea dejando implícitas algunas de las unidades repetidas, recurriendo a vocablos neutros más generales o a marcas anafóricas. Por ejemplo, en el fragmento (1A) la elevada densidad de repeticiones léxicas sirve al autor para destacar la oposición entre lo fácil que le resulta explicar la influencia de su amiga Émilie en su pensamiento filosófico y el esfuerzo que le supone, en cambio, hablar de la influencia de Heidegger:

1)

a) Il m'est très facile de parler de l'influence d'Émilie - aussi, choisissant la facilité, c'est d'elle surtout que je vais parler -, très difficile de parler de l'influence de Heidegger. Autant je cerne aisément la première, autant je cerne mal la seconde.

(Conche 2003: 109 [TO])

b) Me resulta muy fácil hablar de la influencia de Émilie -por eso, como opto por la facilidad, hablaré sobre todo de ella-y muy difícil hablar de la influencia de Heidegger. Tan sencillo me resulta acotar la primera como tan complicado acotar la segunda

(Conche 2010a: 94, traducción de Andújar Moreno [TRAD1])

c) Me resulta muy fácil hablar de la influencia de Émilie -y como, una vez más, me decanto por la facilidad, hablaré sobre todo de ella-y muy difícil hablar de la [Ø] de Heidegger. Tan sencillo me resulta $\underline{\text { acotar la primera como complicado hacerlo }}$ con la segunda

(Conche 2010b: 97, traducción de Andújar Moreno [TRAD_PUBLI])

En (1b) y en (1c) se mantienen las repeticiones del original, salvo la segunda ocurrencia de influence que en el manuscrito se respeta y en la versión publicada se deja implícita. En el texto original, el paralelismo sintáctico destaca la contraposición de los conceptos aisément y mal. Mientras que en (1b) se ha optado por una versión literal donde la estructura morfosintáctica se reproduce palabra por palabra, en el libro publicado se ha rebajado el efecto repetitivo mediante el vocablo más vago hacerlo. Es cierto que, desde el punto de vista semántico, estas leves modificaciones no tienen consecuencias excesivamente importantes para la construcción del sentido textual, pero sí inciden en la dimensión estilística, reducen levemente el énfasis del original y constituyen un indicio de que la repetición léxica y morfosintáctica es un fenómeno incómodo para los responsables de la edición, como puede observarse más claramente en el ejemplo siguiente:

2)

a) Simplifier notre vie est en notre pouvoir, mais pour une part seulement. Ce qui dépend de nous: abolir les «désirs» vains d'Épicure (de gloire, de pouvoir, d'honneurs, d'argent). Ce qui ne dépend pas de nous: le cours du monde, avec tous les événements négatifs pouvant contrarier notre tranquillité [...].

(Conche 2003: 21 [TO]) 
b) Tenemos la facultad de simplificar nuestra vida, pero sólo en parte. Lo que depende de nosotros: abolir los «deseos vanos» de Epicuro (de gloria, de poder, de honores, de dinero). Lo que no depende de nosotros: el rumbo del mundo, con todos los acontecimientos negativos que pueden enturbiar nuestra tranquilidad [...]

(Conche 2010a: 21, traducción de Andújar Moreno [TRAD1])

c) Tenemos la facultad de simplificar nuestra vida, pero sólo en parte. De nosotros depende abolir los «deseos vanos» de Epicuro (de gloria, de poder, de honores, de dinero). Lo que no depende de nosotros es el rumbo del mundo, con todos los acontecimientos negativos que pueden enturbiar nuestra tranquilidad [...]

(Conche 2010b: 23, traducción de Andújar Moreno [TRAD_PUBLI])

Una vez más, en (2a) la construcción sintáctica paralelística sirve al autor para aumentar la fuerza argumentativa de sus aseveraciones, en este caso subrayando una oposición de conceptos. En la versión editada (2c), la traducción literal del manuscrito (2b) se ha modificado mediante una solución más propia de un texto escrito, en el primer miembro del paralelismo, y una oración copulativa que elimina los dos puntos, en el segundo. Esta combinación de soluciones parece responder a la voluntad de deshacer el paralelismo, que podría haberse mantenido fácilmente evitando los dos puntos de (2b), tal vez excesivamente literales, mediante dos oraciones copulativas (Lo que depende de nosotros es [...] y Lo que no depende de nosotros es [...]).

\subsubsection{Orden oracional}

Uno de los principales rasgos de la lengua oral es su sintaxis, que Briz Gómez (1998: 68) denomina "concatenada». Se diferencia de la sintaxis incrustada del escrito en que los enunciados se disponen generalmente a un mismo nivel sintáctico, uno tras otro, conforme van sucediéndose en la mente del hablante. Esta particularidad se plasma en uno de los rasgos sintáctico-estilísticos más destacados del texto estudiado: en el discurso de Conche se observa un orden pragmático propio que destaca por el uso frecuente de la focalización y el realce informativo como recurso para presentar la información tal y como fluye en la mente del autor, o bien para marcar determinados focos de atención. Así, la ordenación de constituyentes textuales en función de factores pragmáticos provoca la anticipación de determinados elementos, sobre todo en un nivel intraenunciativo. En el fragmento (3a), por ejemplo, se observa la anteposición de un complemento circunstancial:

3)

a) Sur ces entrefaites, André Robinet, pour la collection «Philosophes de tous les temps», qu'il venait de fonder chez Seghers, me demanda un «Montaigne» ou un «Voltaire». Je n’hésitai pas.

(Conche 2003: 69 [TO])

b) Entre tanto, André Robinet, para la colección «Filósofos de todos los tiempos», que acababa de iniciar en las ediciones Seghers, me pidió un «Montaigne» o un «Voltaire». No dudé ni un momento.

(Conche 2010a: 57, traducción de Andújar Moreno [TRAD1])

c) Entre tanto, André Robinet me pidió un «Montaigne» o un «Voltaire» para la colección «Filósofos de todos los tiempos», que acababa de iniciar en las ediciones Seghers. No dudé ni un momento.

(Conche 2010b: 64, traducción de Andújar Moreno [TRAD_PUBLI]) 
La traductora advirtió explícitamente a la editorial de la elevada frecuencia de este rasgo sintáctico-estilístico, así como su importante función en la recreación de la lengua oral, y transmitió claramente su decisión de respetarlo en el texto traducido, como se observa en (3b). Sin embargo, en la versión editada se prefiere un orden enunciativo más convencional y lógico (3c). Esta conducta se mantiene de un modo bastante generalizado y casi siempre que aparece una anteposición de este tipo (4a), se normaliza en la versión editada (4c):

4)

a) En 1941, étant élève-maître au lycée de Tulle, alors que nous étions en classe de français, le professeur Paul Teyssier, dont j'ai parlé dans Ma vie antérieure et qui vient de mourir en février 2002, me demanda quel était mon choix politique. Je lui répondis, en toute inconscience (...)

(Conche 2003: 80 [TO])

b) En 1941, cuando estudiaba para maestro en el instituto de Tulle, mientras estábamos en clase de francés, el profesor Paul Teyssier, del que hablé en Ma vie antérieure y que falleció en febrero de 2002, me preguntó cuál era mi opción política. Yo le contesté con toda la inconsciencia del mundo (...)

(Conche 2010a: 68, traducción de Andújar Moreno [TRAD1])

c) En 1941, cuando estudiaba para maestro en la escuela de Tulle, el profesor Paul Teyssier, del que hablé en Ma vie antérieure y que falleció en febrero de 2002, me pregunto cuál era mi opción política en el curso de una de sus clases de francés. Yo le contesté con toda la inconsciencia del mundo (...)

(Conche 2010b: 74, traducción de Andújar Moreno [TRAD_PUBLI])

La modificación del orden expresivo pone de manifiesto la voluntad por parte del editor de alejarse del original para evitar lo que podría considerar «calcos» estilísticos del francés y facilitar la lectura al destinatario presentando la información de una manera lógica, ordenada y convencional. La alteración de la progresión informativa modifica el foco de atención e incide en el ritmo discursivo, además de difuminar un rasgo importante de oralidad fingida en el texto meta.

\subsubsection{Signos de puntuación}

Los cambios editoriales relacionados con los signos de puntuación tienen que ver, una vez más, con la mímesis la lengua oral en el texto traducido y afectan, sobre todo, a indicadores de modalidad como los puntos suspensivos y a los signos de exclamación. Los puntos suspensivos, por ejemplo, permiten marcar en el texto escrito construcciones suspendidas, sincopadas, incompletas o pausas valorativas propias del discurso oral y de la inmediatez comunicativa que le es propia:

La suspensión está originada, bien por la vinculación de los enunciados a la situación comunicativa en la que se emiten, hecho que permite la no verbalización de información evidente o conocida, por lo tanto, innecesaria; o bien por la finalidad expresiva del hablante que posibilita, mediante la suspensión, la obtención de significados múltiples como la intensificación elativa, la potenciación afectiva, etc. (Herrero Moreno 1996: 115, citado en López Serena 2007: 211).

En el texto original, se concentran esencialmente en las intervenciones de Comte-Sponville, siempre destacadas en cursiva, que abren cada capítulo y vehiculan grados diversos de subjetividad. En el pasaje (5A), por ejemplo, el uso de los 
puntos suspensivos tiene la función de marcar una serie inacabada y, por lo tanto, un valor menos subjetivo:

5)

a) Mais ce «scepticisme de fond» ne vaut pas seulement, à mes yeux, pour les autres! Mes propres convictions métaphysiques me paraissent aussi douteuses, ou peu s'en faut, que celles de Pascal, Leibniz, ou Kant (dont je suis, métaphysiquement, si éloigné), ou que les vôtres (dont je suis, à bien des égards, si proche)... C'est pourquoi il m'arrive de comparer la philosophie à un art, plutôt qu'à une science [...].

(Conche 2003: 151 [TO])

b) Pero ese «escepticismo de fondo», en mi opinión, ¡no vale solamente para los demás! Mis propias convicciones metafísicas me parecen igual de dudosas, o casi, que las de Pascal, Leibniz o Kant (del que tan alejado estoy metafísicamente), o que las suyas (de las que, en muchos sentidos, estoy muy cerca)... Por eso en ocasiones comparo la filosofía con un arte y no con una ciencia [...].

(Conche 2010a: 132, traducción de Andújar Moreno [TRAD1])

c) Pero ese «escepticismo de fondo», en mi opinión, no vale solamente para los demás. Mis propias convicciones metafísicas me parecen igual de dudosas, o casi, que las de Pascal, Leibniz o Kant (del que tan alejado estoy metafísicamente), o que las suyas (de las que, en muchos sentidos, estoy muy cerca) [Ø]. Por eso en ocasiones comparo la filosofía con un arte y no con una ciencia [...].

(Conche 2010b: 131, traducción de Andújar Moreno [TRAD_PUBLI])

Mientras que en el manuscrito entregado los puntos suspensivos se respetan de un modo sistemático, pues permiten vehicular efectos discursivos muy similares en francés y en español (5b) y, una vez más, el sistema de la lengua no obliga a alterarlos, en el texto editado se sustituyen por puntos (punto y seguido o punto y aparte) de forma casi generalizada (5c); sobre todo, cuando se acumulan varias ocurrencias en el cotexto cercano, como en el fragmento (6a) donde se actualizan en tres ocasiones:

6)

a) Il m'arrive de me demander si ce n'est pas une façon pour vous de parcourir le territoire que, pendant des décennies, vous aviez considéré comme celui de votre épouse, son domaine réservé, ou préservé, que vous vous interdisiez pour cela et qu'il vous plaît maintenant, après elle, avec elle, d'explorer... Je sais bien que vous avez toujours lu Homère. Mais, il y a dix ans, vous n'en parliez pas de cette façon... Quant à votre belle lecture de Rimbaud, dans Présence de la nature, elle aura sans doute surpris plusieurs de vos lecteurs, qui ne vous savaient pas si sensibles à la poésie, et à cette poésie là...

(Conche 2003: 39-40 [TO])

b) Me llego a preguntar si, para usted, no constituye una manera de recorrer el territorio que, durante décadas, había considerado de su esposa, su ámbito reservado, o preservado, que usted se prohibía por eso mismo y que ahora, después de ella, con ella, le agrada explorar... Sé muy bien que siempre ha leído a Homero; pero hace diez años no hablaba de él así... En cuanto a su espléndida lectura de Rimbaud, en Présence de la nature, seguro que habrá sorprendido a muchos de sus lectores, que no le conocían tan sensible ante la poesía, y ante esa poesía precisamente...

(Conche 2010a: 39, traducción de Andújar Moreno [TRAD1])

c) Me llego a preguntar si, para usted, no constituye una manera de recorrer el territorio que, durante décadas, había considerado de su esposa, su ámbito reservado, o 
preservado, que usted se prohibía por eso mismo y que ahora, después de ella, con ella, le agrada explorar... Sé muy bien que siempre ha leído a Homero; pero hace diez años no hablaba de él así $[\varnothing]$. En cuanto a su espléndida lectura de Rimbaud, en Présence de la nature, seguro que habrá sorprendido a muchos de sus lectores, que no le conocían tan sensible ante la poesía, y ante esa poesía precisamente [Ø].

(Conche 2010b: 41, traducción de Andújar Moreno [TRAD_PUBLI])

De las tres ocurrencias del original (6a), conservadas por la traductora en el manuscrito (6b), el texto editado (6c) mantiene únicamente la primera. En este pasaje, el recurso a los puntos suspensivos indica que se ha dejado intencionadamente implícita una parte del contenido transmitido por el enunciado para que el lector, apoyándose en sus conocimientos, lo recupere mediante inferencia (Figueras Solanilla 2001: 35). El autor transfiere así al lector la responsabilidad de la deducción, una vía interpretativa abierta que queda cerrada en la versión editada mediante el punto y seguido.

Los signos de exclamación también constituyen guías de lectura para el destinatario, pues indican que el enunciado en el que aparecen debe interpretarse como una aserción enfática de tipo subjetivo. Las exclamaciones pueden transmitir una actitud de ironía, sorpresa, indignación, satisfacción o temor por parte del autor, por lo que constituyen una manifestación de su subjetividad. En el texto original, su uso también puede vincularse con la recreación de la lengua oral, puesto que la exclamación indica gráficamente la expresividad y modalidad de unos enunciados que la entonación señalaría en el lenguaje oral (Figueras Solanilla 2001; Alonso Cortés-Manteca 1999). En (7a), por ejemplo, la exclamación trasmite un lamento de Conche:

7)

a) L'homme de l'«intelligence», disait Weil, «ne sait qu'une chose: qu'il n'y a pas de vérité, qu'il existe seulement des vérités», et donc, "qu'il n'y a pas de science audessus des sciences, pas de métaphysique au-dessus des métaphysiques, pas de sagesse au-dessus des sagesses» - et tant pis pour Descartes, pour Kant, pour Hegel! Mais je n'avais pas toujours lu une ligne de Montaigne.

(Conche 2003: 68 [TO])

b) El hombre de la «inteligencia -decía Weil- nada más sabe una cosa: que no hay verdad, que solamente existen verdades» $\mathrm{y}$, en consecuencia, "que no hay ciencia por encima de las ciencias, que no hay metafísica por encima de las metafísicas, que no hay sabiduría por encima de las sabidurías»; y ¡lo siento por Descartes, Kant y Hegel! Pero seguía sin haber leído ni una línea de Montaigne.

(Conche 2010a: 57, traducción de Andújar Moreno [TRAD1])

c) El hombre de la «inteligencia -decía Weil- nada más sabe una cosa: que no hay verdad, que solamente existen verdades» $\mathrm{y}$, en consecuencia, "que no hay ciencia por encima de las ciencias, que no hay metafísica por encima de las metafísicas, que no hay sabiduría por encima de las sabidurías»; y lo siento por Descartes, Kant y Hegel [Ø]. Pero seguía sin haber leído ni una línea de Montaigne.

(Conche 2010b: 64, traducción de Andújar Moreno [TRAD_PUBLI])

La exclamación del original (7a) se transforma en aseveración en la versión editada (7c), con lo que se difumina la ilusión de oralidad y la carga expresiva que vehicula el autor se reduce considerablemente. El tratamiento de las exclamaciones en la versión final revela la misma pauta que ya hemos indicado anteriormente: mientras que en la versión entregada a la editorial se conservan en todos los casos, en el texto editado se modifican y se sustituyen por aseveraciones. 


\subsubsection{Explicitaciones}

La categoría de la explicitación está vinculada a la verbalización de elementos cohesivos que el enunciador debe inferir en el original porque se encuentran implícitos (Klaudy 2008). Así concebida, la explicitación de elementos textuales en el texto publicado entronca directamente con el fenómeno más general de la elipsis o supresión de algún elemento textual, simple o complejo, sin que resulte mermada la claridad global del sentido. Con la elipsis se aligera la redundancia y se reduce la carga que supondría la repetición de determinados elementos textuales susceptibles de ser inferidos por el contexto o la situación enunciativa. Igualmente, se puede utilizar como recurso estilístico para generar diversos efectos discursivos y constituye un importante instrumento de cohesión texual (Halliday y Hasan 1976; Mederos Martín 1988; Hatim y Mason 1995). La voluntad de verbalizar elementos implícitos en el texto pone de manifiesto cómo la elipsis constituye un fenómeno que los responsables de la edición, al igual que los traductores (Chevalier y Delport 1995: 50), tienden a evitar.

\subsubsection{Formas verbales}

La confrontación de los textos del corpus revela que la búsqueda de una mayor explicitud en el texto publicado para facilitar su lectura motiva la explicitación de formas verbales que en el original se eliden. En el ejemplo (8a), Marcel Conche enumera las dos consecuencias del control que ejercen en él la razón crítica y la preocupación por lo racional:

8)

a) Si je ne suis pas poète, ou si peu, ce n'est pas faute de puissance créative et d'imagination, c'est que la raison critique et le souci du rationnel et du raisonnable, voire du «convenable» et du «social», exercent un contrôle si impitoyable sur les produits de mon esprit qu'il en résulte un blocage mental et, pour ce "personnage intérieur» dont parle Cocteau, qui aspire à parler la langue de la poésie, $[\varnothing]$ une incapacité de prendre la parole.

(Conche 2003: 46 [TO])

b) Si no soy poeta, o lo soy tan poco, no es por falta de poder creativo e imaginación, es porque la razón crítica y la preocupación por lo racional y lo razonable, incluso por lo «conveniente» y lo «social», ejercen un control tan despiadado sobre las producciones de mi mente que de ello resulta un bloqueo mental y, para ese «personaje interior» del que habla Cocteau, que aspira a hablar la lengua de la poesía, [Ø] una incapacidad de tomar la palabra.

(Conche 2010a: 38, traducción de Andújar Moreno [TRAD1])

c) Si no soy poeta, o lo soy tan poco, no es por falta de poder creativo e imaginación, es porque la razón crítica y la preocupación por lo racional y lo razonable, incluso por lo «conveniente» y lo «social», ejercen un control tan despiadado sobre las producciones de mi mente que de ello resulta un bloqueo mental y, para ese "personaje interior» del que habla Cocteau, que aspira a hablar la lengua de la poesía, implica una incapacidad de tomar la palabra.

(Conche 2010b: 46, traducción de Andújar Moreno [TRAD_PUBLI])

Puede observarse cómo en el pasaje (8a) el verbo résulter introduce de forma explícita la primera consecuencia (blocage mental), en forma de complemento 
directo. Esta forma verbal se elide cuando se introduce la segunda consecuencia (une incapacité de prendre la parole). El lector debe restituir la elipsis verbal apoyándose en la sintaxis y activando un proceso anafórico que le permita recuperar el verbo del enunciado precedente. Se establece así una mayor dependencia entre ambos elementos, ya que comparten la forma verbal y el segmento elíptico necesita del no elíptico para completar su sentido. En la versión publicada (8c), en cambio, la segunda consecuencia se introduce mediante el verbo implicar, sinónimo de resultar, para evitar la repetición de la misma forma verbal y minimizar así el esfuerzo de procesamiento por parte del lector, que no se ve obligado a activar un proceso de interpretación anafórica.

A diferencia del ejemplo (8a), las explicitaciones más frecuentes en el texto publicado tienen que ver, sin embargo, con elipsis no anafóricas actualizadas en el texto francés. En el discurso Conche se eliden numerosos constituyentes textuales, ya sea para imitar la inmediatez y poca planificación discursiva de la lengua oral, o bien para enfatizar y destacar determinados elementos. Observemos, por ejemplo, la ocurrencia del pasaje (9a), donde el autor describe la importancia de la figura paterna para el desarrollo posterior de su pensamiento filosófico:

9)

a) Or, mon père et moi n'échangions que peu de paroles: si je disais qu'il planait, pour moi, dans une sorte d'Olympe d'où, parfois il abaissait sur moi son regard, ce ne serait pas loin de la vérité. De lui, en général, $[\varnothing]$ ni félicitations, ni reproches, ni enseignements: il me laissait toute liberté d'adhérer à quelque idée que ce soit qui me viendrait à l'esprit.

(Conche 2003: 162 [TO])

b) Pero mi padre y yo sólo intercambiábamos unas pocas palabras: si dijera que, para mí, flotaba en una especie de Olimpo donde, alguna que otra vez, bajaba su mirada y la posaba sobre mí, no andaría muy desencaminado. De él, en general, [Ø] ni felicitaciones, ni reproches, ni enseñanzas: me daba toda la libertad del mundo para suscribir cualquier idea que se me ocurriera.

(Conche 2010a: 143, traducción de Andújar Moreno [TRAD1])

c) Mi padre y yo sólo intercambiábamos unas pocas palabras: si dijera que, para mí, flotaba en una especie de Olimpo donde, alguna que otra vez, bajaba su mirada y la posaba sobre mí, no andaría muy desencaminado. De él, en general, no recibí ni felicitaciones, ni reproches, ni enseñanzas: me daba toda la libertad del mundo para suscribir cualquier idea que se me ocurriera.

(Conche 2010b: 139-140, traducción de Andújar Moreno [TRAD_PUBLI])

La puntuación combinada con la elipsis verbal en (9a) genera un texto nominalizado, que avanza con un ritmo entrecortado y enfático. Dicho efecto, conservado por la traductora en el manuscrito de la traducción (9b) casi palabra por palabra, se difumina en (9c) con la explicitación del verbo recibir. Asimismo, este tipo de explicitaciones, además, al fijar un determinado recorrido interpretativo en el texto publicado, restringen otras posibles interpretaciones del segmento elidido, por lo que inhiben la participación activa del lector en la construcción del sentido; en (9c), por ejemplo, soluciones como no conseguí o no logré podrían ser igualmente válidas, con las diferencias semánticas y de punto de vista que implicarían. 


\subsubsection{Conectores discursivos}

La sintaxis concatenada propia de la lengua oral se caracteriza por la acumulación de enunciados en un mismo nivel sintáctico, sin trabazón explícita entre ellos (López Serena 2007: 211). En la obra estudiada, otro de los rasgos sintáctico-estilísticos en los que esta particularidad se concreta es en la escasa presencia de conectores discursivos, de tal modo que el lector debe deducir las relaciones entre los enunciados activando inferencias a partir del contenido semántico y la contigüidad de los mismos, como ilustra el ejemplo (10a):

10)

a) Je ne m'exprimerais pas tout à fait comme Roger-Pol -qui, d'ailleurs, reconnaît que, sur un fond de non-sens et d'horreur, se détachent des dons sans pareil; [Ø] j'aurais quelques réserves au sujet de ce que certaines de ses formules impliquent.

(Conche 2003: 148-149 [TO])

b) Yo no me expresaría del todo en los términos que utiliza Roger-Pol -un autor que, por lo demás, reconoce que, sobre un fondo de sinsentido y horror, destacan algunos dones sin parangón-; [Ø] tendría algunas reservas sobre lo que implican algunas de sus fórmulas.

(Conche 2010a: 130, traducción de Andújar Moreno [TRAD1])

c) Yo no me expresaría del todo en los términos que utiliza Roger-Pol -un autor que, por lo demás, reconoce que, sobre un fondo de sinsentido y horror, destacan algunos dones sin parangón-; pues tendría algunas reservas sobre lo que implican algunas de sus fórmulas.

(Conche 2010b: 128, traducción de Andújar Moreno [TRAD_PUBLI])

Mientras que en la versión entregada (10b) se mantiene idéntica estructura sintáctica, en la versión publicada (10c) se explicita el nexo causal pues. Este conector impone al nuevo lector una interpretación según la cual el enunciado donde aparece debe entenderse como una justificación o explicación del enunciado precedente. La explicitación de conectores no sólo se produce en el caso de relaciones de causalidad, sino también en las relaciones de oposición (11a):

11)

a) D'œuvrer en philosophe, c'était là ma capacité; $[\varnothing]$ de faire œuvre d'artiste, je ne m'en suis jamais senti capable. Car, pour être musicien, ou peintre, ou sculpteur, ou poète, il faut quelque talent.

(Conche 2003: 153 [TO])

b) Hacer una obra filosófica: esa era justamente mi capacidad; [Ø] de hacer una obra de artista no me he sentido capaz nunca. Y es que, para ser músico, o pintor, o escultor, o poeta, se precisa algo de talento.

(Conche 2010a: 134, traducción de Andújar Moreno [TRAD1])

c) Hacer una obra filosófica: ahí es donde radica precisamente mi capacidad; en cambio, de hacer una obra de artista no me he sentido capaz nunca. Y es que, para ser músico, o pintor, o escultor, o poeta, se precisa algo de talento.

(Conche 2010b: 133, traducción de Andújar Moreno [TRAD_PUBLI])

El significado de procesamiento del conector en cambio (11c), no verbalizado en la versión entregada (11b), indica que debe establecerse un contraste o que existe una contradicción entre los dos miembros vinculados. La explicitación del conector impone una lectura y descarta otras; en (12c), por ejemplo, el conector pero obliga al 
lector a interpretar que es el segundo miembro el que condiciona la continuación del discurso y las inferencias que se desprenden:

12)

a) Ah! Comme la philosophie qui use des ressources de la poésie est plus vivante, plus parlante, plus "secouante»-si je puis dire. Je cite Héraclite. [Ø] Je pourrais citer Bergson (Jeanne Hersch, pour qui tout vrai philosophe a un style, a fait une étude sur le style de Bergson et le rôle, chez lui, de la métaphore et de l'image), Nietzsche, Heidegger.

(Conche 2003: 156-157 [TO])

b) Ay, cómo la filosofía que utiliza los recursos de la poesía es más viva, más elocuente, más «impresionante», si es que puedo expresarlo así. Cito a Heráclito. [Ø] Podría citar a Bergson, (Jeanne Hersh, para quien todo verdadero filósofo tiene un estilo, ha llevado a cabo un estudio sobre el estilo de Bergson y la función, en su pensamiento, de la metáfora y la imagen), Nietzsche, Heidegger.

(Conche 2010a: 137, traducción de Andújar Moreno [TRAD1])

c) Ay, cómo la filosofía que utiliza los recursos de la poesía es más viva, más elocuente, más «impresionante», si es que puedo expresarlo así. Cito a Heráclito; pero podría citar a Bergson, (Jeanne Hersh, para quien toda verdadera filosofía tiene un estilo, ha llevado a cabo un estudio sobre el estilo de Bergson y la función, en su pensamiento, de la metáfora y la imagen), Nietzsche, Heidegger.

(Conche 2010b: 135, traducción de Andújar Moreno [TRAD_PUBLI])

En (12a) no se marca una relación lógica explícita entre Heráclito, por una parte, y Bergson, Nietzsche y Heidegger, por otra. En (12c), en cambio, el conector orienta la lectura para que se interprete que el primer miembro no posee la fuerza argumentativa suficiente para alcanzar la conclusión deseada.

Las relaciones de causalidad y de oposición constituyen el armazón argumentativo del discurso de Conche. El texto francés, el autor obliga al lector a recurrir a la inferencia para interpretar las relaciones lógicas que se establecen entre todo tipo de proposiciones, por lo que consigue implicar más al lector. Al explicitarse los conectores en la versión publicada, se neutraliza un rasgo sintáctico-estilístico de oralidad fingida, se sustituye la yuxtaposición por enlaces más precisos que jerarquizan y ordenan los enunciados y, de este modo, el nuevo lector debe activar un acto interpretativo concreto que inhibe la posibilidad de realizar otro tipo de inferencias.

\subsubsection{Otros mecanismos cohesivos}

Las explicitaciones de otros elementos cohesivos tienen que ver con la búsqueda, en el texto publicado, de enunciados más cohesionados, con unos marcos temporales explícitos y una expresión lógica. El ejemplo (13a) es un fragmento de una secuencia de tipo narrativo donde Conche relata una conversación mantenida con CompteSponville sobre las figuras de Descartes y Montaigne:

13)

a) Quelques années plus tard, alors que nous discutions autour d'un verre, vous me parlez de Descartes comme d'un penseur du Moyen Âge. Je vous regarde, interloqué: «C’est que, me répondez-vous tranquillement j'ai une conception quelque peu extensive du Moyen Âge [...].» Et [Ø] de m'expliquer que Montaigne est le premier penseur de la modernité. 
b) Unos años después, mientras charlábamos tomando algo, me habla de Descartes como un pensador de la Edad Media. Yo le observo, desconcertado: «Lo digo porque -me contesta tranquilamente- tengo una concepción un tanto amplia de la Edad Media [...]». Y [Ø] me explica que Montaigne es el primer pensador de la modernidad.

(Conche 2010a: 56, traducción de Andújar Moreno [TRAD1])

c) Unos años después, mientras charlábamos tomando algo, me habló de Descartes como un pensador de la Edad Media. Yo le miré, desconcertado: «Lo digo porque -me contestó tranquilamente- tengo una concepción bastante amplia de la Edad Media [...]». Y entonces me explicó que Montaigne es el primer pensador de la modernidad.

(Conche 2010b: 63, traducción de Andújar Moreno [TRAD_PUBLI])

En la versión editada (13c) se explicita el adverbio entonces. Esta unidad léxica posee en este ejemplo un valor de organizador continuativo narrativo (Domínguez García 1999). Al expresar que el hecho contenido en el enunciado en que aparece es posterior o inmediatamente posterior al hecho del enunciado precedente, marca la secuencia temporal de las acciones y organiza el progreso discursivo.

La explicitación de marcas anafóricas elípticas constituye otro recurso del editor para señalar más claramente la continuidad entre los enunciados de la versión publicada. En (14c) se explicita el pronombre neutro ello, elíptico en la traducción entregada:

14)

a) On a un certain ressentiment de n'avoir rien eu. Ressentiment injuste si la femme ne nous a laissé aucune illusion? On peut dire «oui». C’est oublier que l'amitié a ses obligations aussi: quand un homme a tellement besoin d'amour que sa vie même lui est souffrance, il appartient à la femme de découvrir en elle une sorte de générosité - qui lui vaudra de la gratitude.

(Conche 2003: 30-31 [TO])

b) Sentimos un cierto resentimiento por no haber conseguido nada. ¿Un resentimiento injusto si la mujer no nos ha dejado ninguna ilusión? Podríamos decir: «Sí». [Ø] Implica olvidar que la amistad también tiene sus obligaciones: cuando un hombre tiene tanta necesidad de amor que su propia vida le genera sufrimiento, corresponde a la mujer descubrir en ella una especie de generosidad, que la hará merecedora de gratitud.

(Conche 2010a: 23, traducción de Andújar Moreno [TRAD1])

c) Sentimos un cierto resentimiento por no haber conseguido nada. ¿Un resentimiento injusto si la mujer no nos ha dejado ninguna ilusión? Podríamos decir: «Sí». Ello implica olvidar que la amistad también tiene sus obligaciones: cuando un hombre tiene tanta necesidad de amor que su propia vida le genera sufrimiento, corresponde a la mujer descubrir en ella una especie de generosidad, que la hará merecedora de gratitud.

(Conche 2010b: 32, traducción de Andújar Moreno [TRAD_PUBLI])

El pronombre ello explicitado en (14c) establece de un modo más claro la conexión interenunciativa. Actúa como una guía interpretativa al desencadenar la instrucción de activar una referencia anafórica amplia, que englobe el contenido semántico de la secuencia previa y las posibles inferencias. Este tipo de pronombres, más propios del medio escrito que del oral, activan una referencia de tipo inconceptual (Fernández Ramírez 1987: 117) y son unidades espacialmente aptas para establecer un proceso 
recursivo amplio cuyo alcance englobe un fragmento textual previo de extensión variable. Sin embargo, la capacidad anafórica de estos pronombres permite dejar bastante indefinidos los límites de la información pertinente para la interpretación del texto. Para facilitar aún más la lectura, cuando en la traducción entregada se hace uso de pronombres neutros (15b), en la versión publicada se explicita el referente mediante unidades léxicas plenas (15c):

15)

a) En philosophie, certes, c'est différent: j'ai bien clairement choisi Épicure contre Platon, Spinoza contre Leibniz et Kant, Marx et Freud (en tant que penseurs, o pensables) contre Nietzsche ou Sartre... Mais je ne vois pas ce que cela retire à la force de leur pensée, quand je m’y oppose, ni à sa fragilité, quand je m'y appuie.

(Conche 2003: 152 [TO])

b) Cierto es que no ocurre lo mismo en filosofía: he preferido claramente Epicuro a Platón, Spinoza a Leibniz y Kant, Marx y Freud (en tanto que pensadores, o pensables) a Nietzsche o Sartre... Pero no veo qué resta ello a la fuerza de su pensamiento, cuando me opongo a ellos, ni a su fragilidad, cuando me apoyo en ellos.

(Conche 2010a: 132, traducción de Andújar Moreno [TRAD1])

c) Cierto es que no ocurre lo mismo en filosofía: he preferido claramente Epicuro a Platón, Spinoza a Leibniz y Kant, Marx y Freud (en tanto que pensadores, o pensables) a Nietzsche o Sartre... Pero no veo qué resta mi elección a la fuerza de su pensamiento, cuando me opongo a ellos, ni a su fragilidad, cuando me apoyo en ellos.

(Conche 2010b: 131, traducción de Andújar Moreno [TRAD_PUBLI])

La anáfora por nominalización del texto editado (15c), al transformar en referente el proceso expresado por los enunciados anteriores, minimiza el esfuerzo cognitivo del lector e implica una mayor explicitud léxica en el texto final.

\section{Conclusiones}

El análisis contrastivo de la obra Confession d'un philosophe, del filósofo francés Marcel Conche, el manuscrito de la traducción castellana y la versión finalmente publicada en forma de libro ha puesto sobre el tapete la importancia de los cambios introducidos por la editorial en el manuscrito de la traducción, que afectan esencialmente a la mímesis de la lengua oral. La ilusión de oralidad no se produce en el texto francés tanto por el uso de vocablos o expresiones coloquiales sino más bien por la recurrencia de elementos sintáctico-estilísticos como el empleo de la repetición o la elipsis como instrumentos de cohesión discursiva, la abundancia de signos de puntuación indicadores de modalidad, como los puntos suspensivos o la exclamación, o la ordenación de los constituyentes enunciativos en virtud de factores pragmáticos que provocan la anticipación de determinados elementos. Mientras que en la versión entregada a la editorial estos rasgos distintivos se reproducen de un modo casi literal, porque no son dependientes del sistema de la lengua sino opciones discursivas que forman parte del proyecto de escritura del autor, en la versión publicada se han aplicado modificaciones y explicitaciones con la intención de dotar al texto final de un mayor grado de cohesión que facilite al lector su procesamiento. Al igual que las conductas traductoras no son sistemáticas sino graduales, las divergencias introducidas 
por la editorial no son totalmente homogéneas, sino que también pueden describirse en términos de tendencias más o menos recurrentes.

Hemos concebido el concepto de normalización en este estudio no como una técnica de traducción concreta sino como una actitud general de los responsables editoriales que se explica por su voluntad, consciente o inconsciente, de querer construir un nuevo texto más convencional y claro, que minimice el riesgo comunicativo facilitando al lector un recorrido interpretativo balizado (recuperando la instrucción explícita de la editorial: «que se lea bien»). Esta normalización se concreta, principalmente, en las modificaciones y explicitaciones que hemos descrito en el trabajo. La intervención editorial que ha revelado el estudio de caso podría enmarcarse en una estrategia general de fluidez (Venuti 1995), por la cual se considera aceptable una traducción cuando la ausencia de cualquier tipo de particularidad lingüística hace aparentar transparencia. Por consiguiente, la decisión traductora de mantener los recursos expresivos propios del discurso de Conche de un modo literal o casi literal no ha sido bien recibida por la editorial, que ha preferido un texto cohesionado de forma explícita y susceptible de ser interpretado por el lector con un mínimo esfuerzo cognitivo. Como contrapartida, el estilo del autor y la recreación de la lengua oral que le es propia resultan mermados en la versión publicada.

El diseño del estudio de caso, aunque a nuestro juicio ofrece datos interesantes, adolece de algunas debilidades metodológicas de las que somos plenamente conscientes y que, en futuros trabajos, nos proponemos subsanar. En primer lugar, en aras de respetar al máximo la validez ecológica y la objetividad experimental, resulta fundamental que el traductor y el analista no sean la misma persona. De lo contrario, es fácil que las conclusiones que se alcancen pierdan consistencia por culpa del efecto Rosenthal. Aunque el estudio de caso, tal y como está concebido, ha permitido acceder al manuscrito de la traducción, un documento difícil de conseguir de otro modo, pues las editoriales no suelen conservarlos, así como un mayor conocimiento sobre las condiciones concretas del encargo, convendría obtener textos personales de otros traductores, o bien directamente de las propias editoriales.

En segundo lugar, en futuros estudios se hace necesario analizar de forma más precisa las diversas fases de emergencia de la versión publicada para distinguir el grado de responsabilidad del corrector y del editor en los cambios introducidos. Dicho de otro modo, debe establecerse claramente si las modificaciones y explicitaciones son voluntad del corrector, que las introduce al comparar con el original y el editor, posteriormente, las recibe de buen grado; o bien si, por el contrario, es el editor quien las introduce en el texto corregido en una última revisión previa a la publicación. Eludir esta distinción implica simplificar el proceso de producción editorial y minimizar el papel de correctores y editores en la autoría múltiple de la traducción publicada. Esta limitación podría subsanarse manteniendo entrevistas con el editor y con la persona o personas encargadas de la corrección para tratar de analizar dicho proceso.

A pesar de las limitaciones de esta primera exploración, los datos preliminares obtenidos en la confrontación de los textos permiten corroborar que la actitud normalizadora en la que se enmarcan las modificaciones y explicitaciones detectadas no siempre es atribuible al traductor. Los estudios traductológicos contrastivos que analizan textos del ámbito editorial ofrecen una vía de análisis muy valiosa, pues se apoyan en datos reales, pero deberían incluir también en la ecuación la función de 
correctores y editores en la configuración del producto final. Como ha mostrado el estudio de caso, el traductor puede encontrarse en una posición secundaria como parte integrante de la cadena del libro, pues, como apuntaba Francí Ventosa (2015), éste no siempre está informado de las transformaciones que sufre su manuscrito, ni se encuentra en disposición de negociar dichas transformaciones mediante una interlocución directa con correctores y editores. Profundizar en esta vía de análisis incorporando a los estudios contrastivos manuscritos de las traducciones, como nos proponemos hacer en un futuro, permitiría identificar normas de edición explícitas o implícitas vinculadas a las condiciones que impone la editorial al traductor y describir con mayor precisión el complejo proceso de emergencia de un libro traducido.

\section{AGRADECIMIENTOS}

Agradecemos a la Dra. Anna Espunya Prat el habernos facilitado las referencias bibliográficas que han permitido reorientar el marco teórico del trabajo y a Julio Caminero González sus indicaciones para el diseño y elaboración de la figura 1.

\section{NOTAS}

* La autora de este trabajo forma parte del proyecto ValTrad (La valoración en traducción), con número de referencia FFI2013-42751-P, financiado por el Ministerio de Economía y Competitividad (MINECO), 2014-2017. El proyecto se inscribe, a su vez, en el marco del grupo de investigación consolidado CEDIT (Centro de Estudios de Discurso y Traducción), con número de expediente 2014 SGR 843, concedido por la AGAUR de la Generalitat de Catalunya.

1. Según Ana María Rojo López (2013: 43), los estudios de caso se conciben en traductología de un modo abierto y flexible, pues se incluye en esta rúbrica casi cualquier análisis traductológico donde se trabaje con datos empíricos reales. El análisis contrastivo aquí presentado destaca por su carácter contextual y su imbricación en el mundo real de la traducción editorial profesional.

2. A lo largo del estudio utilizaremos los términos «editor»y «editorial», entendiendo por ellos la persona física o jurídica que pone los medios materiales económicos para divulgar una obra (Luna Alonso 2013: 133).

3. Conche, Marcel (2003): Confession d’un philosophe. Réponses à André Comte-Sponville. París: Albin Michel.

4. Conche, Marcel (2010a): Confesiones de un filósofo. Respuestas a André Comte-Sponville (traducido del francés por Gemma AndújAR Moreno). Versión entregada a Ediciones Paidós Ibérica por la traductora.

5. Conche, Marcel (2010b): Confesiones de un filósofo. Respuestas a André Comte-Sponville (traducido del francés por Gemma AndúJAR Moreno). Barcelona: Paidós. Versión publicada.

6. En los ejemplos comentados, estos tres documentos se identifican como TO, TRAD1 y TRAD_ PUBLI respectivamente.

7. Real Academia de la Lengua (2014): «manuscrito». Dicccionario de la lengua española. Madrid: Espasa.

8. No estamos en disposición de determinar si los cambios efectuados en el manuscrito con respecto al libro comercializado son atribuibles al corrector o al editor de mesa, por lo que nos hemos referido a ellos de un modo genérico como «correcciones editoriales». Somos conscientes de que esta circunstancia constituye una limitación del análisis (Toury 1995: 183) que retomaremos en las conclusiones del trabajo.

9. Su catálogo incluye autores como Zygmunt Bauman, Erich Fromm, Edward de Bono, Jeremy Rifkin, Vasili Kandinsky, Howard Gardner, André Comte-Sponville, Naomi Klein o Michael Walzer, entre otros. Véanse <www.planetadelibros.com/editorial-ediciones-paidos-3.html $>$ o bien $<$ http://www. planeta.es/es/ES/AreasActividad/Editoriales/Grupo-Planeta/Ediciones-Paidos.htm>.

10. Véase, por ejemplo, MAGGiori, Robert (2014): L'épicure d'Altillac. Libération. 29 de octubre de 2014.

11. Ministerio de Educación, Cultura y Deporte. Base de datos de libros editados en España. Consultado el 8 de junio de 2015, <http://www.mecd.gob.es/cultura-mecd/areas-cultura/libro/ bases-de-datos-del-isbn/base-de-datos-de-libros.html>. 


\section{REFERENCIAS}

Alonso-Cortés Manteca, Ángel. (1999): Las construcciones exclamativas. La interjección y las expresiones vocativas. In: Ignacio Bosque y Violeta Demonte, dirs. Gramática descriptiva de la lengua española. Vol. 3. Madrid: Espasa-Calpé, 3993-4050.

BAKer, Mona (1993): Corpus Linguistics and Translation Studies: Implications and Applications. In: Mona Baker, Gill Francis y Elena Tognini-Bonelli, eds. Text and Technology: In Honour of John Sinclair. Amsterdam: John Benjamins, 233-250.

Bakker, Matthijs, Koster, Cees y Van Leuven-Zwart, Kitty (1998): Shifts of translation. In: Mona BAKer, ed. Encyclopedia of Translation Studies. Londres/Nueva York: Routledge, 226-231.

BECHER, Viktor (2010a): Abandoning the notion of "translation-inherent" explicitations: against a dogma of Translation Studies. Across Languages and Cultures 11(1):1-28.

BECHER, Viktor (2010b): Towards a more rigorous treatment of the explicitation hypothesis in Translation Studies. Trans-kom 3(1):1-25.

BisiadA, Mario (2014): 'Lösen Sie Schachtelsätze möglichst auf': The impact of editorial guidelines on sentence splitting in German business article translations. Applied Linguistics. Consultado el 22 de junio de 2015, <http://applij.oxfordjournals.org/content/early/2015/06/01/ applin.amu035.full.pdf?keytype=ref\&ijkey=DtUumMPKecm7Bep>.

Briz Gómez, Antonio (1998): El español coloquial en la conversación: esbozo de pragmagramática. Barcelona: Ariel.

Bush, Peter (2006): The Writer of Translations. In: Peter Bush y Susan Bassnetr, eds. The Translator as Writer. Londres: Continuum, 23-32.

Chesterman, Andrew (2000): A Causal Model for Translation Studies. In: Maeve Olohan, ed. Intercultural Faultines. Research Models in Translation Studies I: Textual and Cognitive Aspects. Manchester: St. Jerome, 15-28.

Chevalier, Jean-Claude y Delport, Marie-France (1995): L'Horlogerie de Saint Jérôme. Problèmes linguistiques de la traduction. París: L'Harmattan.

Domínguez García, Noemí (1999): La organización del discurso escrito en español actual. Los marcadores temporales. In: Lingüística para el siglo XXI. III Congreso organizado por el Departamento de lengua española. Universidad de Salamanca: Ediciones de la Universidad de Salamanca, 465-476.

Dragovic-Drouet, Mila (2005): L'apport de la notion de traduction éditoriale à une typologie de l'activité traduisante. In: Jean Peeters, ed. La traduction. De la théorie à la pratique et retour. Rennes: Presses Universitaires de Rennes, 151-158.

Fernández Ramírez, Salvador (1987): Gramática española. Madrid: Arco/Libros.

Figueras Solanilla, Carolina (2001): Pragmática de la puntuación. Barcelona: Octaedro, Ediciones Universitarias de Barcelona.

Filippakopoulou, Maria (2008): Translation Drafts and the Translating Self. In: Nikolaou PAschalis y Maria-Venetia Kyritsi, eds. Translating Selves: Experience and Identity Between Languages and Literatures. Londres: Continuum, 19-36.

Fouces González, Covadonga (2011): La traducción literaria y la globalización de los mercados culturales. Granada: Comares.

Francí Ventosa, Carmen (2015): Elogio del corrector. El paratraductor (y 2). El Trujamán. Consultado el 21 de julio de 2015, <http://cvc.cervantes.es/trujaman/anteriores/julio_15/ 17072015.htm>.

Goetsch, Paul (2003): The Oral and the Written in Nineteenth-Century British Fiction. Frankfurt am Main: Peter Lang.

Hale, Terry (2001): Publishing strategies. In: Mona BAKer, ed. Routledge Encyclopedia of Translation Studies. Londres/Nueva York: Routledge, 190-194.

Halliday, Michael y Hasan, Ruqaiya (1976): Cohesion in English. Londres: Longman.

Hatim, Basil y Mason, Ian (1995): Teoría de la traducción. Una aproximación al discurso. Barcelona: Ariel Lenguas Modernas. 
Herrero Moreno, Gemma (1996): La importancia del concepto de enunciado en la investigación del español coloquial: a propósito de enunciados suspendidos. In: Pragmática y gramática del español hablado. Actas del II Simposio sobre análisis del discurso oral. Valencia: Universidad de Valencia, 109-126.

Hurtado Albir, Amparo (2001): Traducción y traductología. Introducción a la traductología. Madrid: Cátedra.

Jones, Francis (2006). Unlocking the Black Box: Researching Poetry Translation Processes. In: Manuela Perteghella y Eugenia Loffredo, eds. Translation and Creativity: Perspectives on Creative Writing and Translation Studies. Londres: Continuum, 59-74.

KLAUdy, Kinga (2008): Explicitation. In: Mona BAKER, ed. Routledge Encyclopedia of Translation Studies. Londres/Nueva York: Routledge, 80-84.

Koch, Peter y Oesterreicher, Wulf (2007): Lengua hablada en la Romania: español, francés, italiano (traducido del alemán por Araceli López SerenA). Madrid: Gredos.

KRUGer, Haidee (2012): A corpus-based study of the mediation effect in translated and edited language. Target 24(2):355-388.

Laviosa-Braithwaite, Sara (1998): Universals in Translation. In: Mona Baker, ed. Routledge Encyclopedia of Translation Studies. Londres/Nueva York: Routledge, 288-291.

López Serena, Araceli (2007): Oralidad y escrituralidad en la recreación literaria del español coloquial. Madrid: Gredos.

Luna Alonso, Ana (2013): Perspectivas de investigación en traducción editorial. Romanica Olomucensia 25(2):127-143.

Olohan, Maeve (2004): Introducing Corpora in Translation Studies. Londres: Routledge.

MaIer, Carol (2007): The translator as an intervenient being. In: Jeremy Munday, ed. Translation as intervention. Londres: Continuum, 1-17.

Mauranen Anna y Kujamäki, Pekka, eds. (2004): Translation Universals. Do They Exist? Amsterdam/Filadelfia: John Benjamins.

Mederos Martín, Humberto (1988): Procedimientos de cohesión en el español actual. Excmo. Ayuntamiento de Santa Cruz de Tenerife: Cabildo Insular de Tenerife.

Munday, Jeremy, ed. (2007): Translation as Intervention. Londres: Continuum.

Munday, Jeremy (2013): The role of archival and manuscript research in the investigation of translator decision-making. Target 25(1):125-139.

NeunZig, Wilhelm y Tanqueiro, Helena (2007): Estudios empíricos en traducción: enfoques y métodos. Barcelona: Universitat Autònoma de Barcelona.

NidA, Eugene A. (1997: Translation in the information age. In: Marian B. LABrum, ed. The Changing Scene in World Languages. Amsterdam: John Benjamins.

Pijuan Vallverdú, Alba (2007). Anàlisi del mecanoscrit i la correcció de la traducció de Manuel de Pedrolo de Llum d'agost. Quaderns 14: 57-66.

Pym, Anthony (2008): On Toury's Laws on how Translators Translate. In: Anthony Pyм, Miriam Shlesinger y Daniel Simeoni, eds. Beyond Descriptive Translation Studies. Investigations in Homage to Gideon Toury. Amsterdam: John Benjamins, 311-328.

Rojo López, Ana María (2013): Diseños y métodos de investigación en traducción. Madrid: Síntesis.

Sánchez Orozco, Pilar (20013): Actualidad de una sabiduría trágica: el pensamiento de Marcel Conche. Tesis doctoral. Madrid: Universidad Nacional de Educación a Distancia.

Toury, Gideon (1995): Descriptive Translation Studies and Beyond. Amsterdam: John Benjamins.

Toury, Gideon (2004): Probabilistic explanations in Translation Studies: Universals or a challenge to the very concept? In: Gyde Hansen, Kirsten Malmkjaer y Daniel Gile, eds. Claims, Changes and Challenges in Translation Studies. Amsterdam: John Benjamins, 15-25.

Venuti, Lawrence (1995): The Translator's Invisibility. A History of Translation. Routledge: Londres/Nueva York.

Zanettin, Federico (2012): Translation-driven Corpora. Manchester: St. Jerome. 